\title{
Zoning release of heavy metals in the ground water of Karaj plains, Tehran
}

\author{
Leila Rostami Bairagh ${ }^{1}$ and Fatemeh Nasehi* \\ ${ }^{1}$ Department of Environmental Science, Ardabil Branch, Islamic Azad University, Ardabil, Iran
}

\begin{abstract}
In studies of groundwater, the issue of quality as well as quantity has particular importance, and as long as conditions of groundwater quality and quantity in different dimensions such issues are not analyzed, it cannot explain the general characteristics of the aquifer. In this study, to investigate the heavy metal pollution in Karaj plain, first, from 59 selected source of plains were sampled and the samples were analyzed using atomic absorption. Map of the metal pollution refers to segregation were prepared. After the analysis conducted on selected samples of Karaj plain, concentration maps for heavy metal cadmium, lead, copper, cobalt was prepared for seasons to seasons probe and low-water of plain. According to classical statistics, as well as the results statistically significant difference between the stations were obtained in terms of the concentration of these elements. The results showed that there are significant differences between the two seasons. In view of the heavy metals concentration maps of the southern part of the plain interpolation sampling points was observed in terms of emissions is much higher than the average standard of the World Health Organization. Stations located in the southern plains, such as Safar Abad Fashafouiyeh, Mahmoud Abad, Ghanbar Abad, Ghamsar, Kahrizak, Hesar-e Chupan and etc. in all the elements in this study were plain compared to the upstream areas of concentration and excessive pollution. But certainly in the long-term trend of groundwater contamination and no space will be followed by many environmental risks.
\end{abstract}

KEY WORDS: ZONING, HEAVY METALS, PLAIN, GROUNDWATER

\section{INTRODUCTION}

Generally, the processes of harvesting, refining, transport and consumption of oil has severe pollution potential and, if discharged to the environment, it results in severe contamination of soil, air, surface and ground- water. Generally, oil spills on land which penetrate into the ground water issue is not a new issue any more. In Iran, due to the presence of fuel tanks, contamination of groundwater aquifers, petroleum and behavior of pollutants is important. Considering the fact that in addition to the majority of agricultural land irrigated by under-

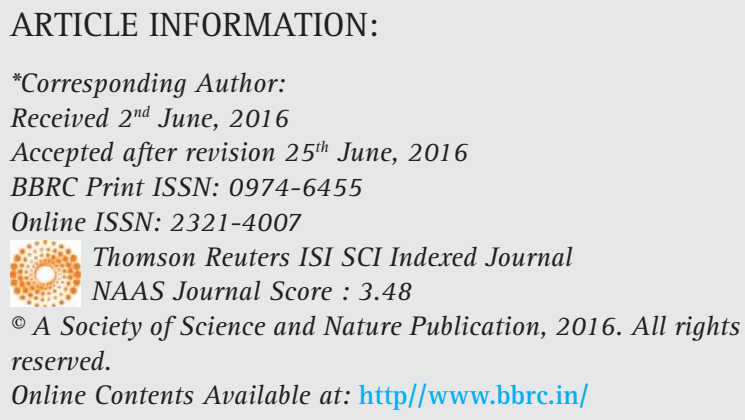


ground wells, are used for drinking (Asadollah Fardi, 2010). Water is the most important inorganic compound for living cells and life of all living things depend on it. Today, with the population growth, reducing pollution and increasing per capita water conservation physical, chemical and biological water, the water crisis has been proposed as one of the major worldwide problem (Ministry of Health and Medical Education Department of Health, 2010 and Dabiri, 2013).

Especially in recent decades, the most important concern of people living on Earth, especially in arid and semi-arid countries such as Iran, is the issue of water supply with appropriate quality and quantity. On the other hand, there are focuses on increasing public sensitivity and awareness about the environment and achieve sustainable development. Thus, a balance between environmental goals and comprehensive approach to water quality prior conditions, along with its quantity has been required (Rezaei, 2011).

Water pollution is the result of the addition of any foreign body in such a way that the quality of its physical, chemical or biological change it so that it could be harmful for human consumption and agriculture and other creatures and man cannot even ordinary water treatment, water supply to provide its own life. In other words, when water is contaminated or its composition, either directly or indirectly as a result of human activity changed and this change will cause other than that for applications that previously could not be used in normal mode (Fataei, 2011).

Access to safe drinking water is an essential requirement of any society. Population growth, expanding cities and industries etc. has caused the pollution of the environment, especially water resources for drinking (Hajizadeh, 1998). Groundwater pollution is one of the most important environmental issues of geology, especially in areas where surface water exist or are lacking. Unfortunately, due to the invisibility of groundwater, a lot of people about their importance and they are not aware of the harmful effects of environmental pollution (Davis, 1994). The number of combinations for elements of heavy metal toxicity mineral known for years. These materials contain the most toxic materials in the environment, including lead, mercury, cadmium and nickel. These metals accumulate in living organisms and remain for a long time as the sum of the toxin acts (Dabiri, 2013).

Heavy metals as a result of weathering of rocks and soil and volcanic activity and human ecosystems to find their ways (Khatami, 2007). Cyclical changes and chemical point of view, having regular control program to predict the water quality of the river seems necessary. In addition to the detection and characterization of small pollution sources for effective control of contaminants and the proper management of water resources is essential (Listory, 1990). In a study of Malakoutian et al conducted in 2014 as arsenic concentrations of heavy metals cadmium, lead and copper in drinking water supplies in rural southeastern plains of Rafsanjan, stated that the contaminants in the water that excessive amounts of heavy metals which makes the development of various diseases and in all cases of lead and cadmium is above the standard level, (Malakoutian et al 2014).

In another study of Eghbali Shams Abadi et al (2010) conducted on heavy elements chromium, cadmium, lead and organic matter in the White River with a view of the structural geological origin, the workers stated cadmium and lead concentrations were close to limit or more, the study of industrial activities and urban and rural sewage discharge due to pollution of river sediments to determine cadmium and lead. Due to the large area and multiple sources of hazardous wastewater discharges to groundwater with heavy metals in this area and in parts of the aquifer is quite uncertain. On the other hand a large proportion of industrial wastewater is mainly in the fields of Karaj Special Road and Old Road, where wastewater discharged to surface, flows through local rivers fed by underground water leaks, so there is no information about the infected zones. Necessary measures in this regard, and with little information regarding the use of new research in this area and use GIS tools will have to be developed.

\section{MATERIAL AND METHODS}

\section{INTRODUCTION OF THE STUDY AREA}

Tehran and Shahriar basin plains is located in north central Iranian plateau. The basin in the 45-51 45- ${ }^{\circ} 50$ 'east longitude coordinates $15-^{\circ} 35$ north latitudes to $15-36$. The study area includes plains aquifer and Shahriar Tehran are the sum of a unit at the complex hydrological and hydraulic connection with each other. In order to explain the characteristics and identifying and distinguishing them individually to explain the details of each of aquifers and then provide a map of the integrated water these features is an evaluated. In Figure 1, schematic position three regions aquifer is presented.

In this study, the study area was divided using the network almost to a 59 network. In each grid or a pixel sampling stations (as much as possible from the network) is selected and a total of 59 networks and 59 sampling stations in the selected area, in addition to network dimensions are $5 \times 5$ meters. This type of study is analytical. Chemical analysis results in Excel as a database was saved. Position wells were recorded using GPS for maps and entered into the Arc GIS software. 


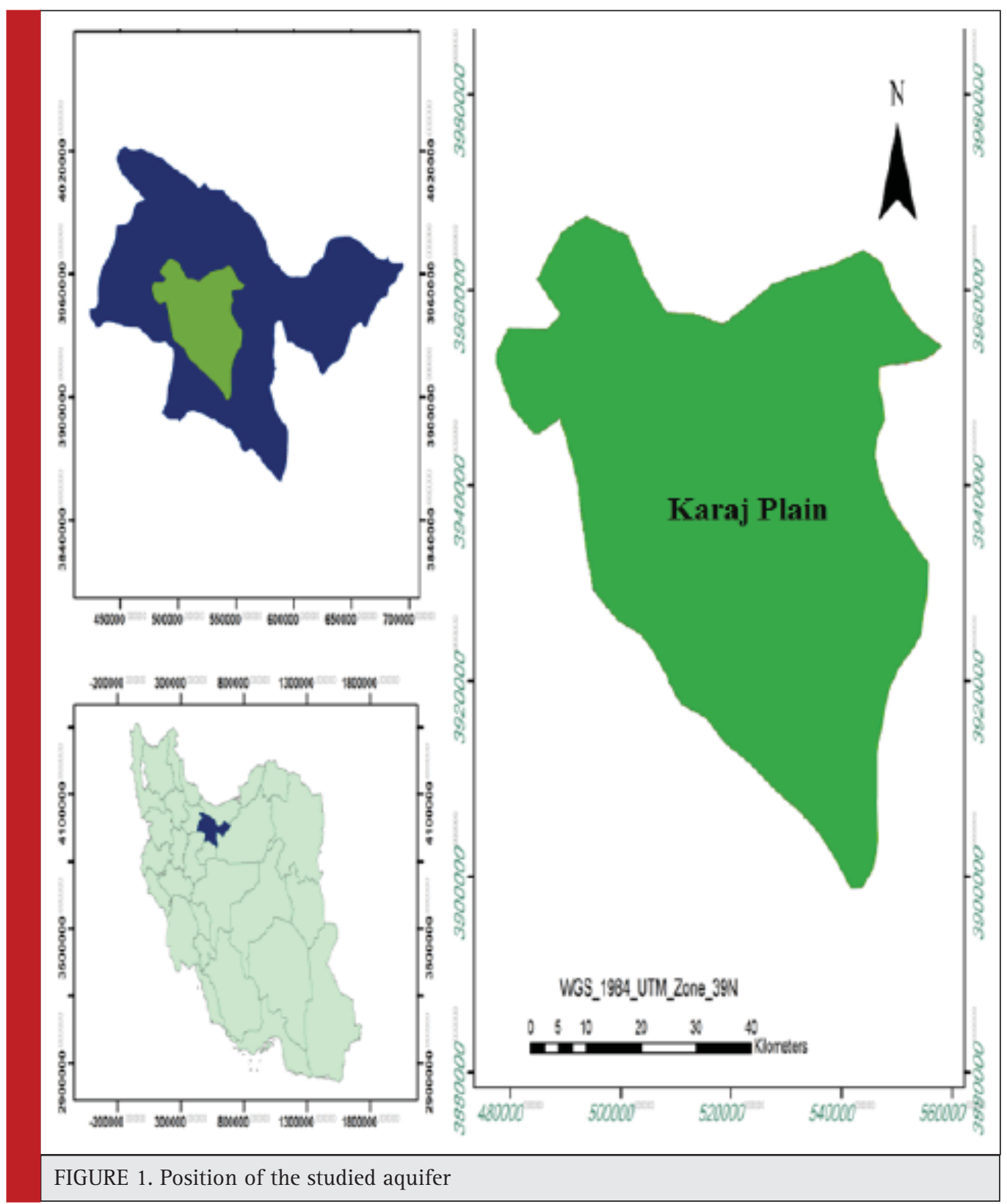

\section{RESULTS AND DISCUSSION}

\section{ZONING MAPS OF THE STUDY AREA}

Investigation of zoning maps of heavy metals cadmium, cobalt, copper, lead, chromium in Tehran - Karaj plain after reviewing the most optimal interpolation algorithm zoning map of the concentration of ions, cadmium, cobalt, lead, chromium was prepared using Arc GIS software. Figures (3) to (10) map of the location and amounts of heavy metals in the study area shows changes in both spring and summer.
Map prepared based on cadmium on hand to highwater seasons suggest that the rate of metal concentrations in groundwater in the range of 0.082 to 28.9 micrograms per liter. In other words, a large part of the plains in the high water has a concentration less than the limit specified in the WHO (0.003) drinking water standard of Iran (0.01), however, southern parts of the greater concentration.

Rezvani et al (2013) found similar results in a study were similar in Eshtehard plain. Map prepared based on cadmium concentration of Karaj plain blue for low seasons suggest that the rate of metal concentrations 

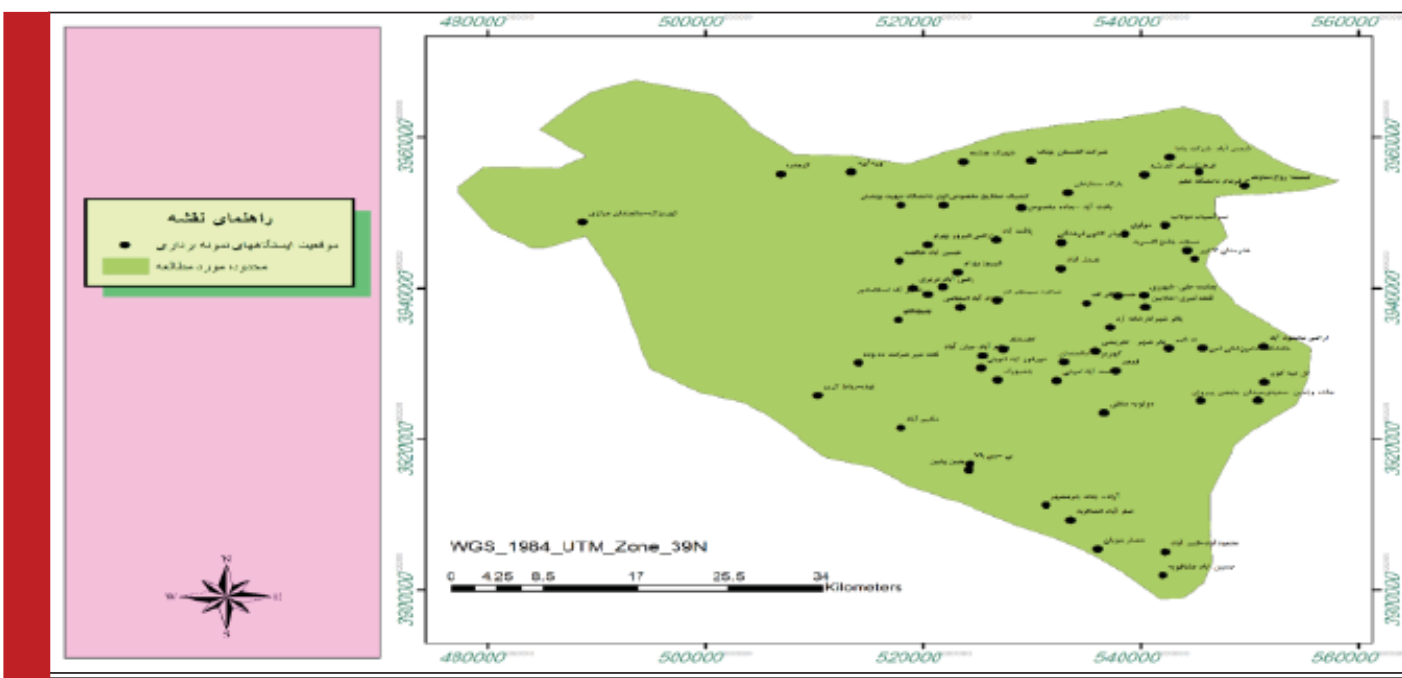

FIGURE 2. Shows the position of studied stations in Tehran - Karaj plain. Map of cadmium concentration for high-water and low-water seasons

in groundwater in the range of 0.053 to 17.5 micrograms per liter. In other words, a large part of plain water in low season with less than the maximum permissible concentration determined in the WHO (0.003) drinking water standard Iran (0.01), however, southern parts of the greater concentration. In addition to the plain of the disease than seasonal high water pollu- tion has been reduced and the area less than plain on the seasons of the year have been infected. However, the wet season and low water contamination in almost the same way. It seems disposal of wastewater from the wells, causing a sharp increase in the concentration of cadmium in groundwater in the southern extent of the plain.

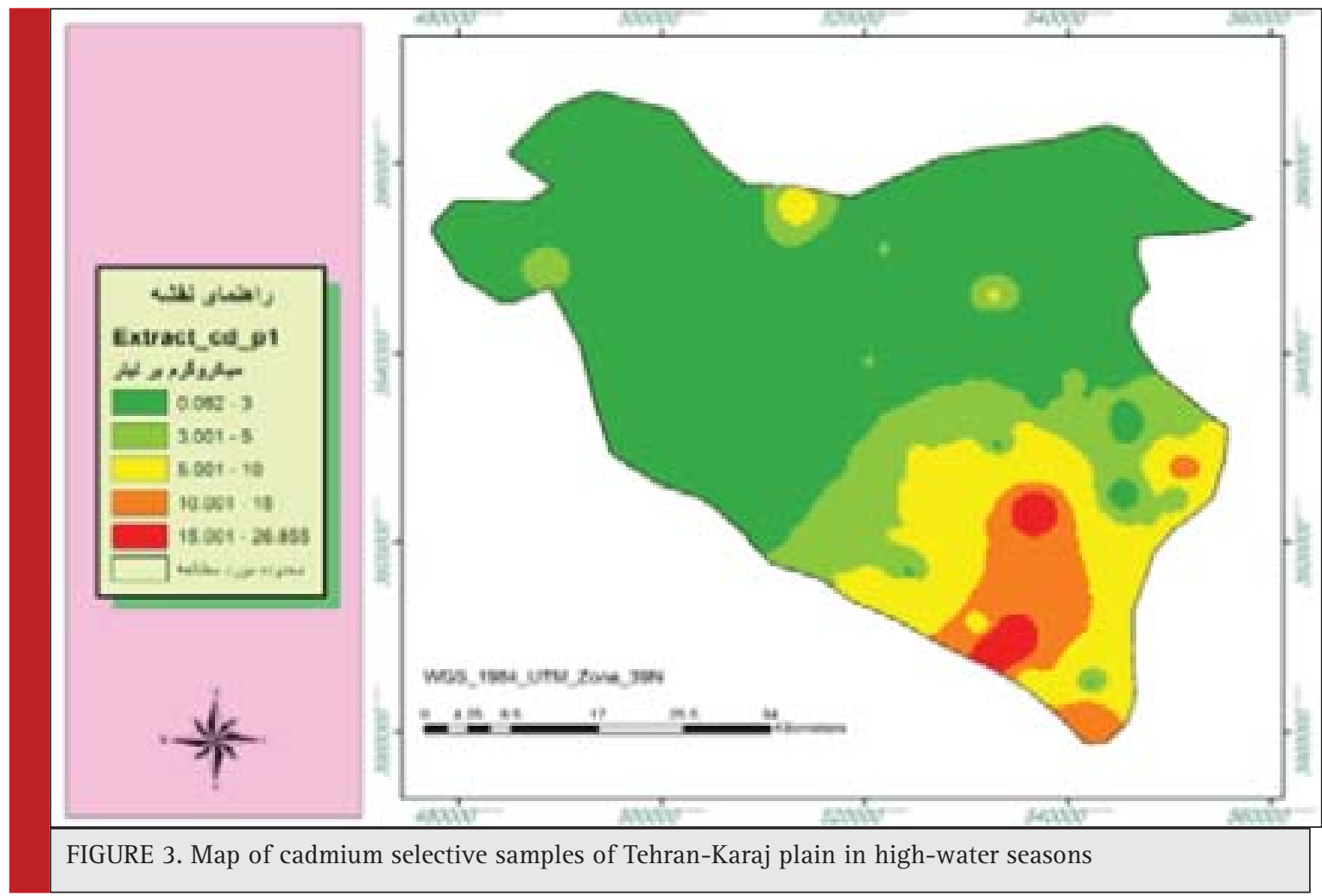



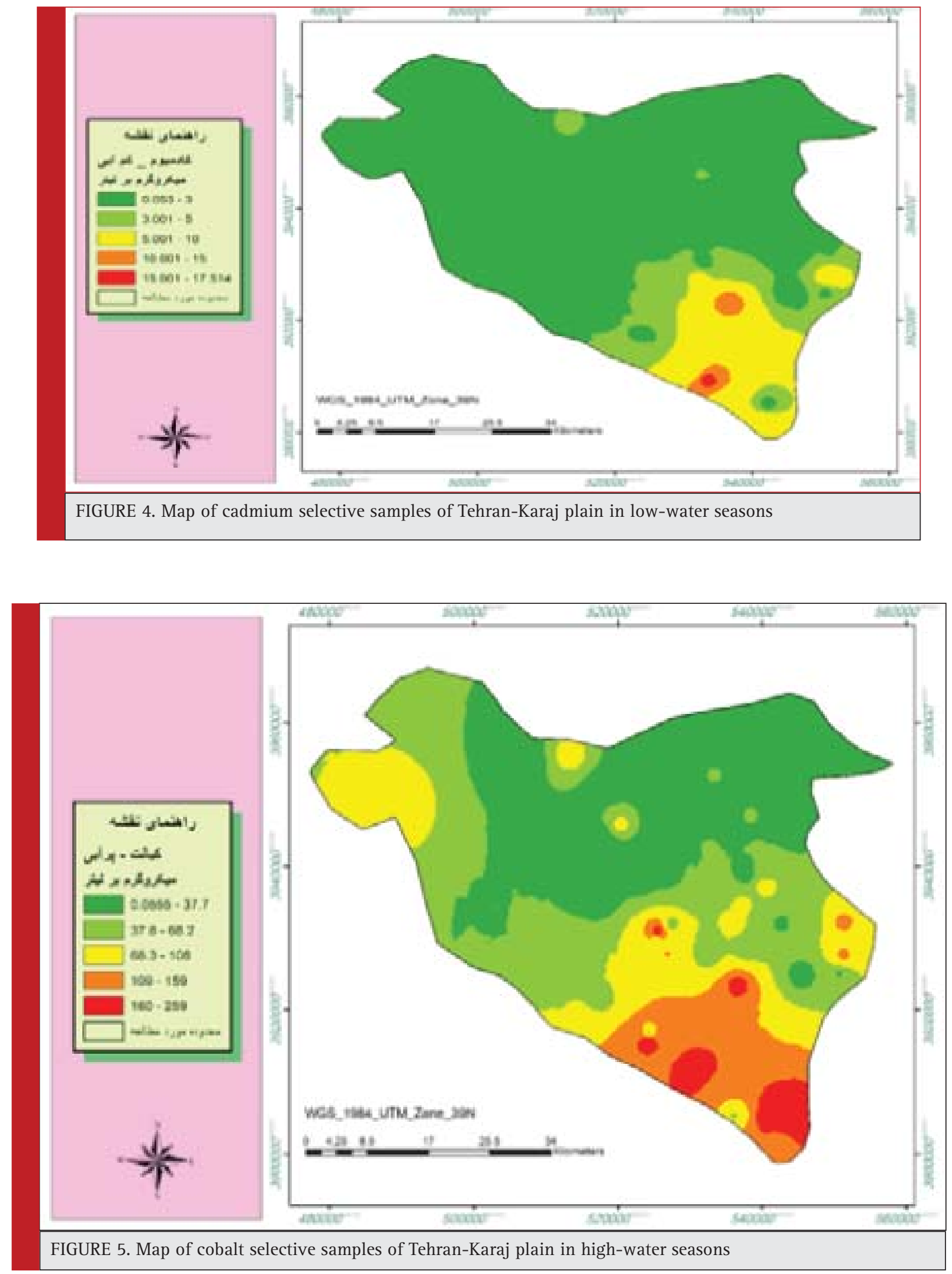

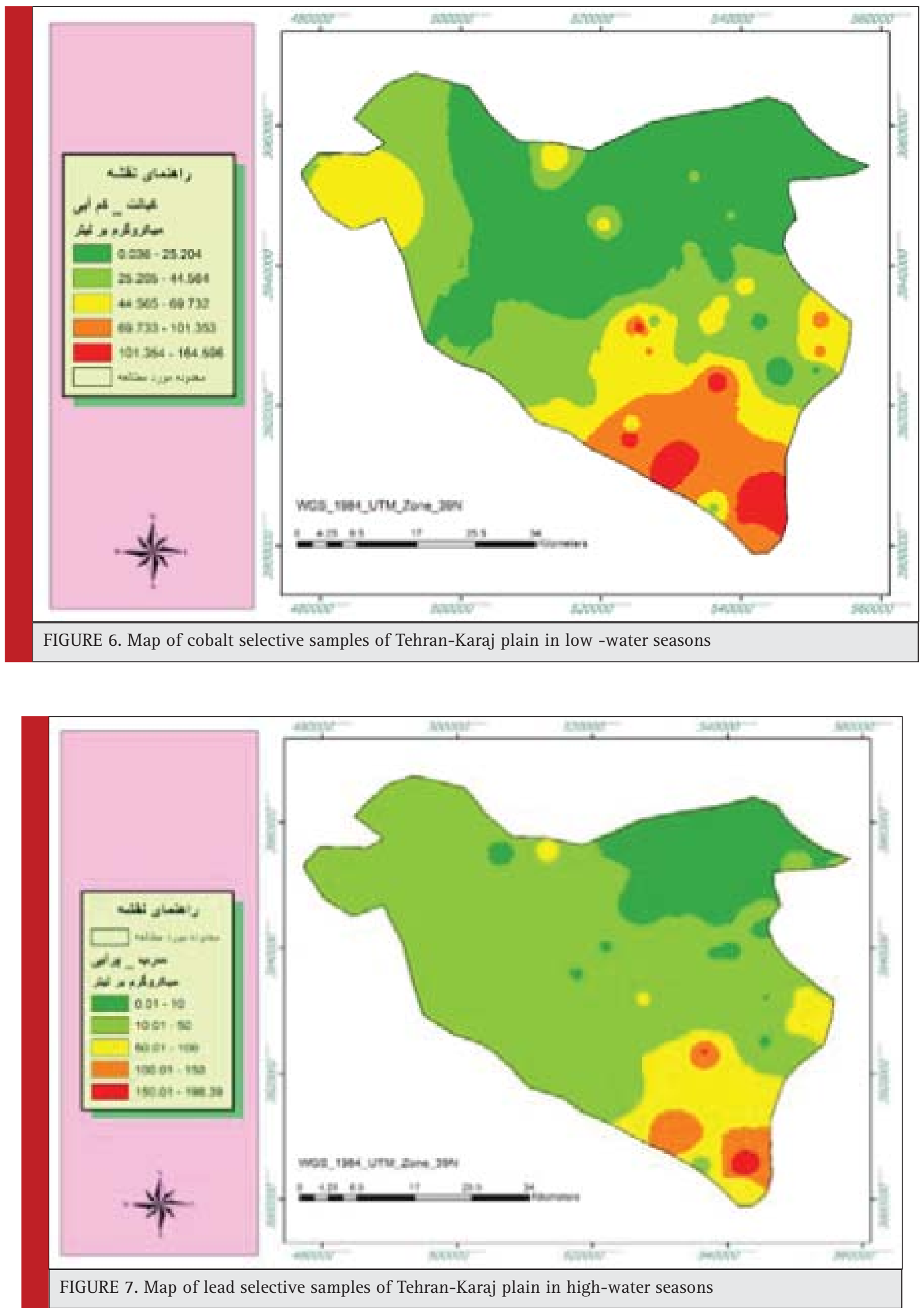

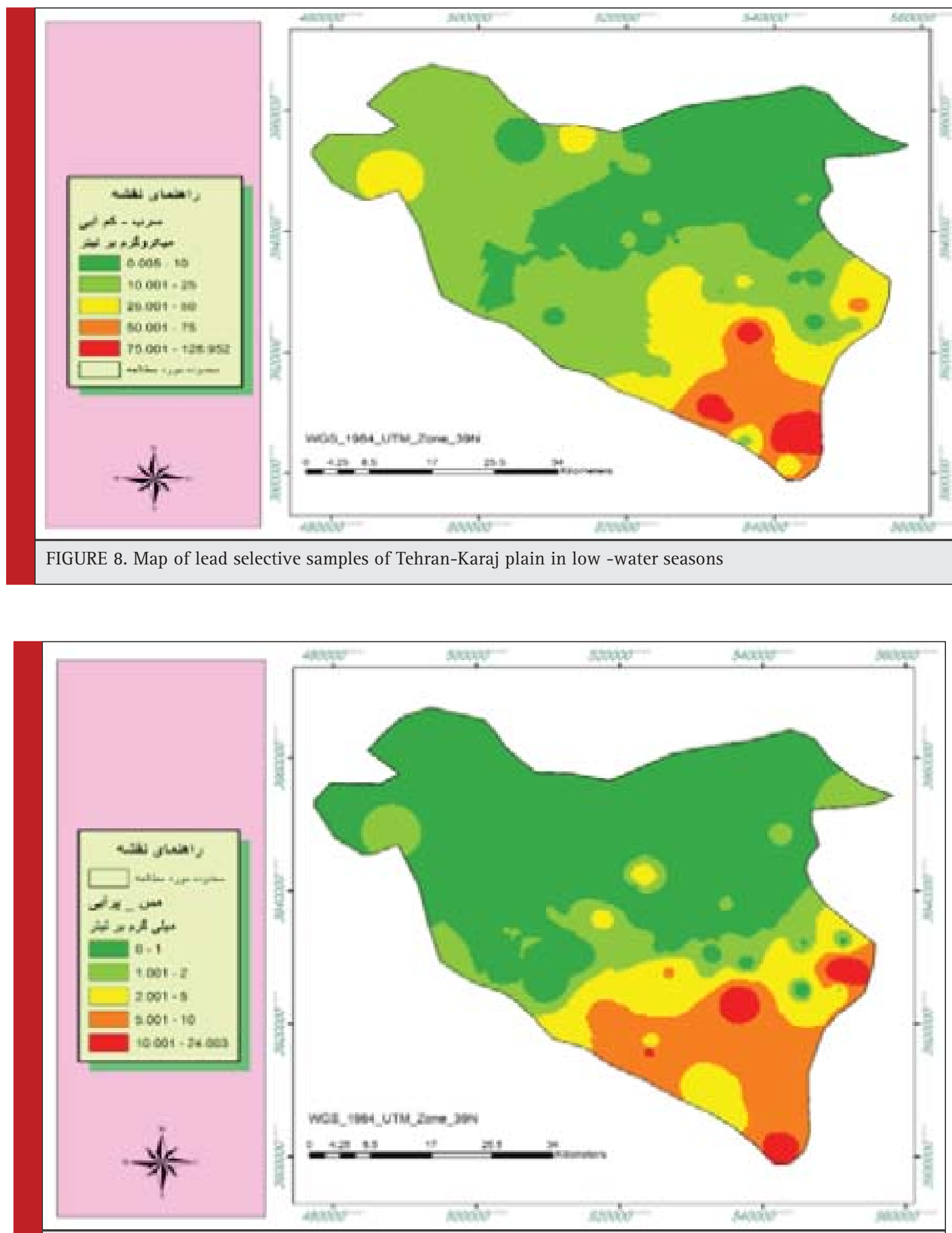

FIGURE 9. Map of copper selective samples of Tehran-Karaj plain in high-water seasons 


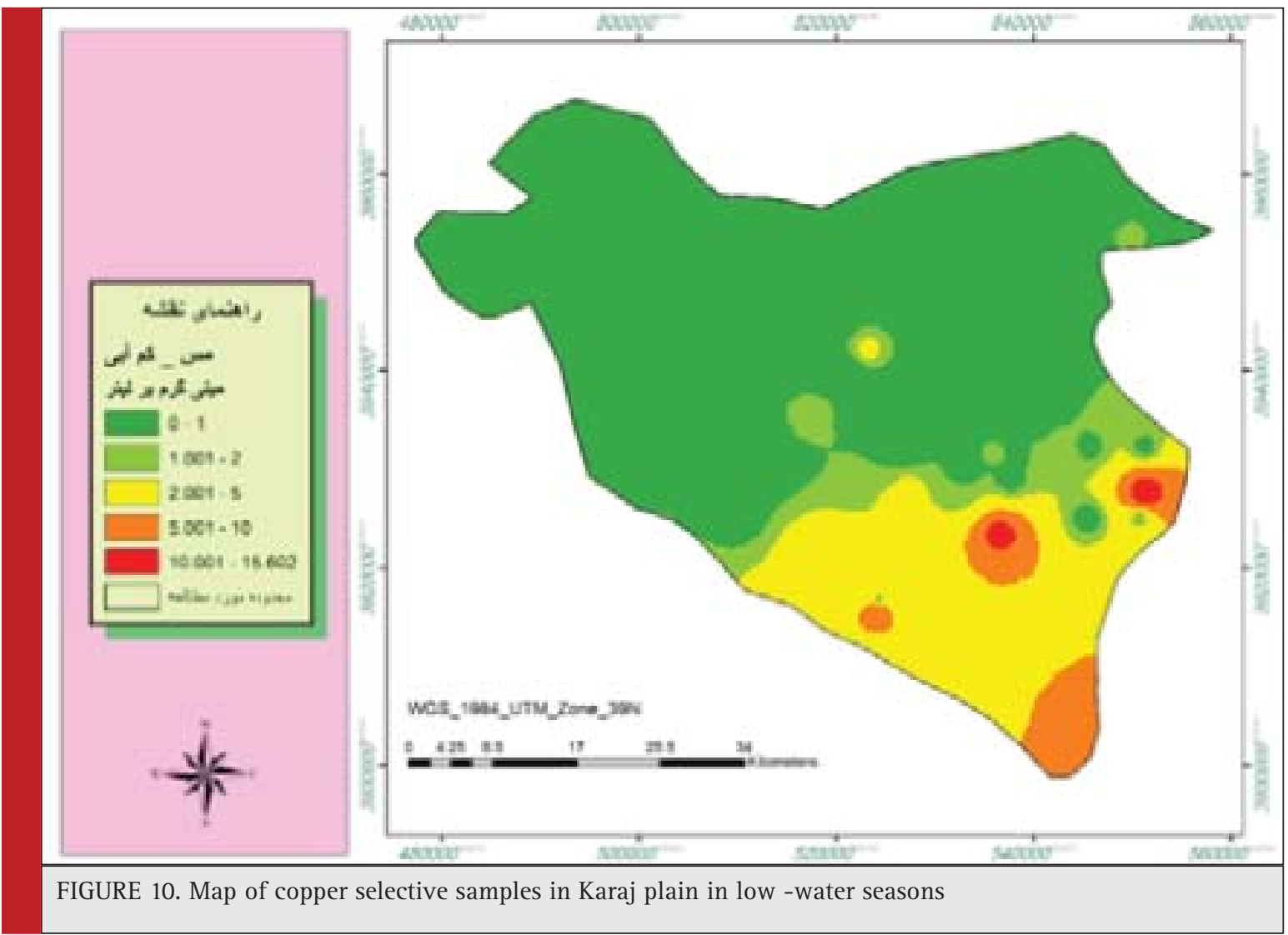

\section{MAP OF COBALT CONCENTRATION FOR HIGH- WATER AND LOW-WATER SEASONS}

Due to the lack determine the maximum allowable concentration of cobalt metal underground water standards, there is no contamination on the plains; however, in the southern extent of the plain for both seasons, sharp increase of cobalt concentration is observed which is mainly caused by groundwater discharge of sewage and industrial workshops. Map prepared based on cobalt concentration in the hands of Tehran-Karaj plain for high-water seasons suggest that the rate of metal concentrations in groundwater in the range of 0.05 to 259 micrograms per liter. In other words, a large part of the plains in the high water season has low concentration, however, the southern part of plain has more concentration. In addition plain disease severity has been reduced than the seasonal high water pollution. These changes are slight changes, especially in the southwestern part of the plain area of less than plain on the seasons of the year have been infected. However, the wet season and low water pollution in quite the same way. Map prepared based on cobalt concentration in Karaj plain for low-water seasons suggest that the rate of metal concentrations in groundwater in the range of 0.03 to 164 micrograms per liter.

\section{MAP OF LEAD CONCENTRATIONS FOR HIGH- WATER AND LOW-WATER SEASONS}

Map of lead concentrations of Karaj plain aquifer indicate that the vast majority far from if or in other words is very low. However, in the southern part of the border and out of plain concentrations of this element out of Iran and the World Health Organization standard is extremely high. This situation is true both for high-water and low-water seasons. However, in seasons of low water pollution has been reduced in view of the plain area. In other words, the area contaminated areas is greater than the area of polluted areas in the high water season in low water season and vice versa. Map prepared based on the concentration of lead in Karaj plain for high-water seasons indicate that the concentrations of these metals in groundwater in the range of 0.01 to 198 micrograms per liter and for low-water seasons in the concentration range is 0.005 to 129 .

\section{MAP OF COPPER CONCENTRATION FOR HIGH- WATER AND LOW-WATER SEASONS}

Map of copper concentration in Karaj plain didn't show that significant emissions but the zoning maps show abnormal increase is observed in the southern part of 
the plain. Workshop industrial site in south and disposal of sewage and paint manufacturing foundries through absorption and enter groundwater through wells has been increasing copper concentration in these sectors. Map prepared based on copper concentrations of Karaj plain in high-water seasons indicates that the metal concentrations in groundwater suggest that the rate ranging from zero to 24 milligrams per liter. In other words, a large part of the plains in the high water has lower concentrations particularly northern parts, however, the southern plains has low concentration. In addition plain disease severity has been reduced to the seasonal high water pollution, despite these changes, particularly changes in the southern part of the plain area of less than plain on the seasons of the year have been infected. However, the high-water and low-water seasons pollution in quite the same way. Map prepared based on copper concentrations in Tehran-Karaj plain were also evaluated for low-water seasons and indicate that the concentrations of these metals in groundwater in the range of zero to 15 milligrams per liter.

\section{CONCLUSION}

Investigation of groundwater of Tehran-Karaj plain was made from an environmental standpoint. In view of the heavy metal concentration maps of interpolated sampling points were observed, and found that south of the plains is seen in terms of emissions above the average standard of the World Health Organization. Map prepared based on cadmium concentration in the hands of the low-water seasons indicates that the concentrations of these metals in groundwater are in the range of 0.082 to 28.9 micrograms per liter. The concentration of cadmium in Tehran - Karaj plain for low-water seasons indicates that the concentrations of these metals in groundwater is in the range of 0.053 to 17.5 micrograms per liter. It seems sewage disposal equipment through absorption wells has caused a sharp increase in the concentration of cadmium in groundwater in the southern extent of the plain. Cobalt concentration in Karaj plain to high water seasons suggest that the rate of metal concentrations in groundwater in the range of 0.05 to 259 micrograms per liter. Cobalt concentration of Karaj plain blue for low seasons suggest that the rate of metal concentrations in groundwater in the range of 0.03 to 164 micrograms per liter. Lead concentrations in water of Karaj plain to high-water seasons of metal concentrations in groundwater suggest that the rate of up to 198 micrograms per liter in the range of 0.01 to 0.005 to 129 of low water seasons concentration is in this range. Copper concentrations of Karaj plain for high-water seasons indicate that the concentrations of these metals in groundwater in the range of zero to 24 milligrams per liter. Copper concentrations in Karaj plain also were investigated for low-water seasons and indicate that the concentrations of these metals in groundwater in the range of zero to 15 milligrams per liter. The results of the surveys indicate that plain pollution with heavy metals is not a hazard but in areas of severe changes in some metals is visible.

\section{REFERENCES}

Asadollah Fardi, GR, God-Ahmad, Yaghoubi M. (2010). MTBE transfer parametric study of Tehran's fuel tanks into groundwater resources. Iran, Water Resources Research. Pp. 1-11.

Dabiri, M. (2013). Environmental pollution (air -B -Khak -Svt) publishing the first edition Union, Eighth Edition.

Davis,A., J.H.,Kempton, \&t A.,Nicholson.( 1994). Ground water transport of arsenic and chromium at a historical tannery, Applied Geochemistry, Vol. 9, pp. 569-582.

Eghbali Shams Abadi, P. (2010). Evaluation of heavy metals chromium, cadmium, lead and organic matter in the White River with a view on the origin of their structure, specialized scientific journal Wetlands Islamic Azad University of Ahvaz (3).

Fataei, E, (2011). Recognition of Natural Resources and the Environment, Ardebil Islamic Azad University Press, first edition.

Hajizadeh, J. (1998). determining the contamination of underground sources of drinking water Tabriz in terms of heavy metals Master of Environmental Health, School of Health, Tehran University of Medical Sciences Pub..

Khatami, SH. (2007). Self-purification of the river, publications Environmental Protection Agency EPA USA

Listori, j. 1990. Environmental Health Components for Water supply. Sanitation and Urban Projects.Washington DC:Worldwide Bank.

Malakoutian, M., (2014). Evaluation of heavy metals arsenic, cadmium, lead and copper in drinking water supplies in rural southeastern plains of Rafsanjan, in the Journal of Public Health, Vol 7 (1).

Ministry of Health and Medical Education Department of Health, Center for Environmental Health (2009). Recipes and physicochemical methods of measurement of inorganic toxic chemicals in drinking water, MHMMED HC Env. Health 2009

Rezaei Bennis, N. (2011). Evaluation of the quality of water in the reservoir Asrparamtrhay Sdmart, First International Conference and the National Conference of dams and hydroelectric power plants, Tehran, Iran

Rezvani, M., (2013). The evaluation of heavy metal pollution cadmium, cobalt, lead, zinc, manganese Bkhvn Eshtehard, Environmental Science and Engineering, No. 1. 